\title{
Espécies novas de Otiothops e Fernandezina do norte do Brasil (Araneae, Palpimanidae)
}

\author{
Erica H. Buckup \& Ricardo Ott
}

Museu de Ciências Naturais, Fundação Zoobotânica do Rio Grande do Sul, Rua Dr. Salvador França, 1427, 90690-000, Porto Alegre, RS, Brasil. (erica@fzb.rs.gov.br; aracno@fzb.rs.gov.br)

ABSTRACT. New species of Otiothops and Fernandezina from northern Brazil. Otiothops lajeado sp. nov. and Fernandezina saira sp. nov., respectively from the states of Tocantins and Amazonas, Brazil, are described.

KEYWORDS. Otiothopinae, Fernandezina, Otiothops, taxonomy, Neotropical.

\section{INTRODUÇÃO}

O gênero neotropical Otiothops MacLeay, 1839 contém 33 espécies, das quais 20 ocorrentes no Brasil. Cinco espécies são conhecidas para o norte do país, seis do nordeste e quatro do centro-oeste; no sudeste e sul estão assinaladas duas espécies para cada região (PLATNICK, 1975, 1976, 1977, 1978, 1985; PlATNICK et. al., 1999; BRESCOVIT \& BonAldo, 1993; GRISMADO, 1996, 2002; WundERLICH, 1999).

Fernandezina Birabén, 1951 inclui nove espécies neotropicais, das quais seis registradas para o Brasil e uma respectivamente para Guiana, Peru e Argentina (BIRABÉN, 1951; Platnick, 1975; Ramírez \& Grismado, 1996; Platnick et al., 1999; GRISMADO, 2002).

Espécimes examinados estão depositados na coleção de aranhas do Museu de Ciências Naturais, Fundação Zoobotânica do Rio Grande do Sul (MCN, curadora E. H. Buckup), Porto Alegre, e no Instituto Nacional de Pesquisas da Amazônia (INPA, curador Célio Magalhães), Manaus. Descrições seguem Platnick $(1975,1977)$. Medidas estão em milímetros.

\section{Otiothops lajeado sp. nov. (Figs. 1, 3-5)}

Tipo. Holótipo 3 , Serra do Lajeado, Palmas, Tocantins, Brasil, XI.1992, E. H. Buckup col. (MCN 22663).

Etimologia. O substantivo em aposição é alusivo à localidade-tipo.

Diagnose. Otiothops lajeado assemelha-se às espécies do grupo germaini pelo êmbolo longo e largo, clavado (Platnick, 1975, figs. 37, 39, 41, 43), mas distinguese dessas espécies pelo ápice do êmbolo estreito com projeções (figs. 3-5).

Descrição, macho (fig. 1). Comprimento total, 6,40. Carapaça, comprimento 2,60, largura 1,65. Fêmur I, comprimento 1,90, altura 0,85 . Olhos médios posteriores, ovalados, quase contíguos. Carapaça, quelíceras, esterno, lábio e escudo abdominal castanho-avermelhados, pernas amarelo-claras, exceto coxa e trocanter I, alaranjados. Dorso e ventre do abdômen, amarelo-esbranquiçados; metade póstero-dorsal do abdômen levemente avermelhada.

\section{Fernandezina saira sp. nov. \\ (Figs. 2, 6-8)}

Tipo. Holótipo ơ, EMBRAPA, Centro de Pesquisa Agroflorestal da Amazônia Ocidental (CPAA), Rodovia AM 010, km 30, Manaus, Amazonas, Brasil, 10.IX.1997, Equipe Shift ENV-52 col. (INPA).

Etimologia. O nome específico é uma combinação arbitrária de letras.

Diagnose. Fernandezina saira, similar a F. takutu Grismado, 2002 (GRISMADO, 2002, figs. 1-3), distingue-se desta pelo palpo do macho com êmbolo reto e liso (figs. 6-8).
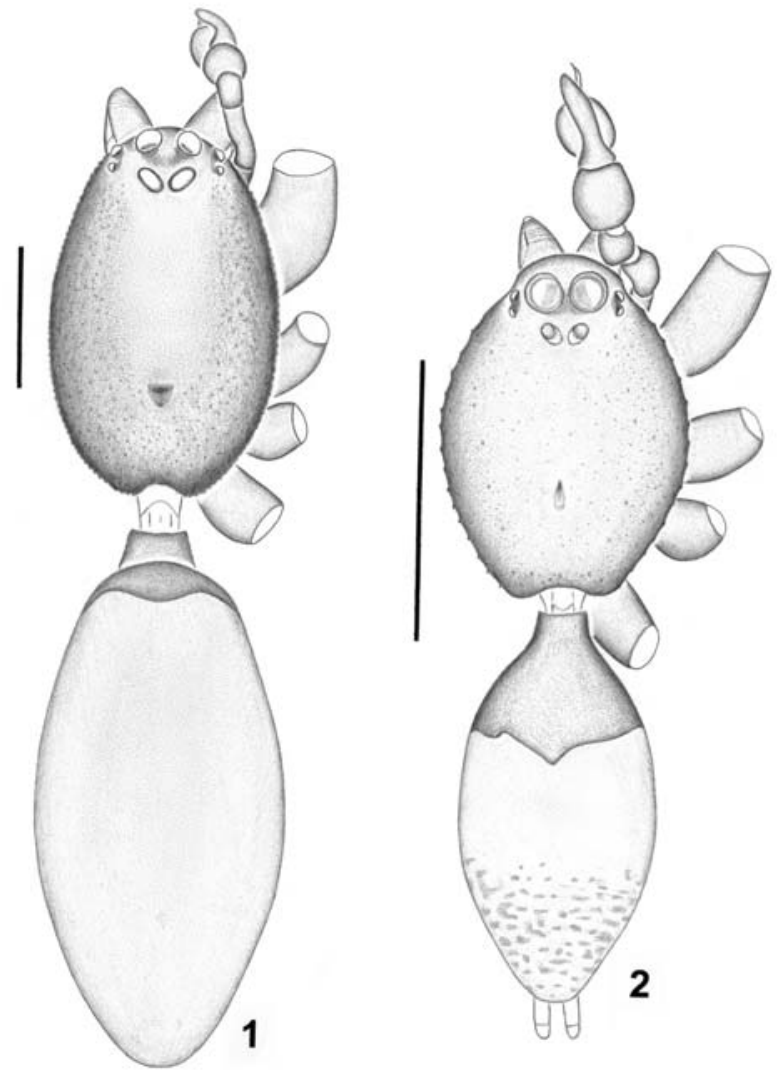

Figs. 1, 2. 1, Otiothops lajeado sp. nov., macho, dorsal. 2, Fernandezina saira sp. nov., macho, dorsal. Barras: $1 \mathrm{~mm}$. 

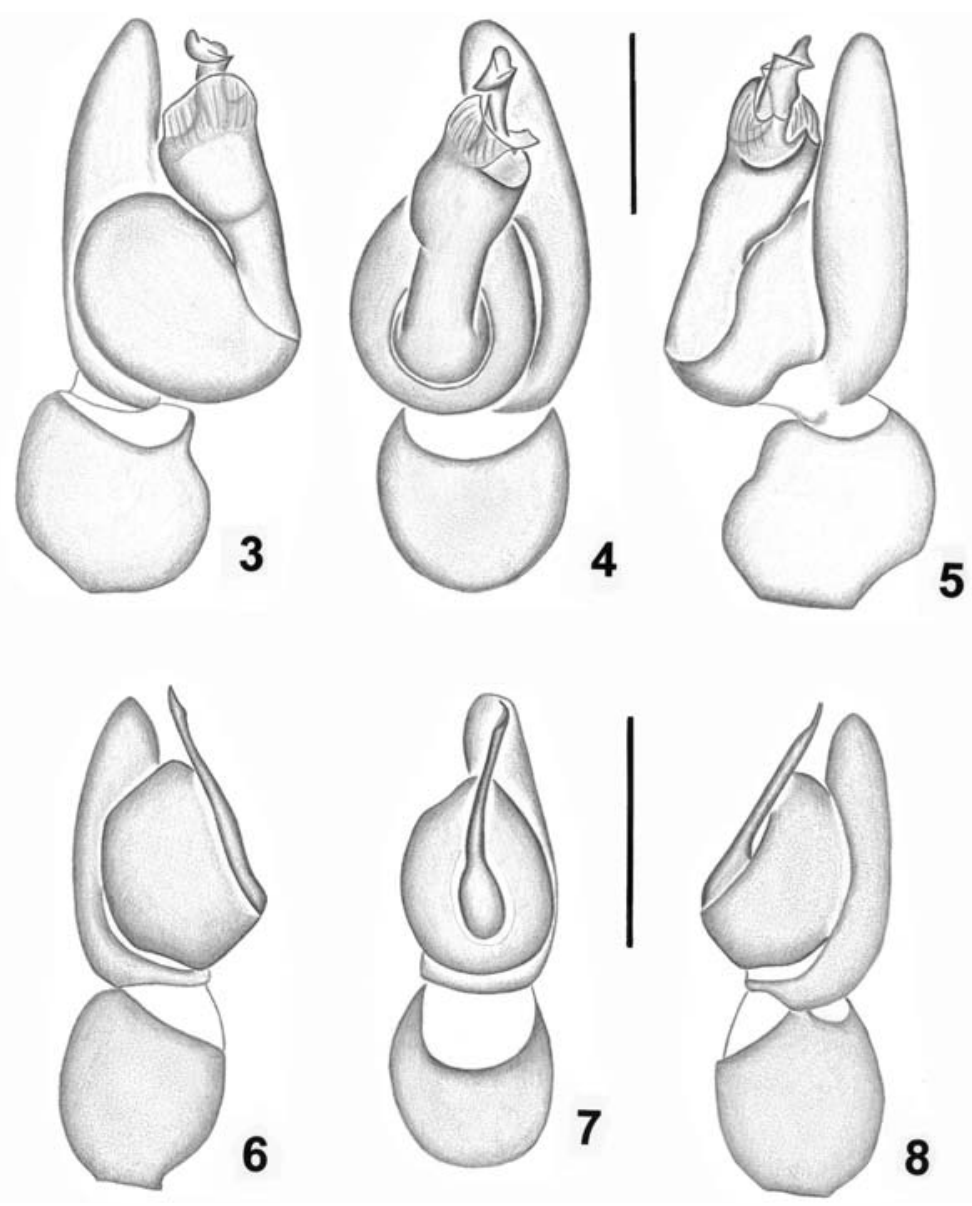

Figs. 3-8. Otiothops lajeado sp. nov., palpo do macho: 3, prolateral; 4, ventral; 5, retrolateral. Fernandezina saira sp. nov., palpo do macho: 6, prolateral; 7, ventral; 8, retrolateral. Barras: 0,25 mm; figs. 3-5 e 6-8, respectivamente nas mesmas escalas.

Descrição, macho (fig. 2). Comprimento total, 2,60. Carapaça, comprimento 1,22, largura 0,87. Fêmur I, comprimento 1,35 , altura 0,30 . Olhos médios posteriores ovalados, separados por cerca da metade do seu eixo transversal. Escudo abdominal cobrindo aproximadamente $40 \%$ do dorso do abdômen. Carapaça e escudo abdominal castanho-avermelhados; pernas amarelo-claras, exceto fêmur I, amarelo-escuro nos artículos basais até a tíbia. Abdômen amarelo-esbranquiçado, metade póstero-dorsal com inúmeras manchas irregulares marrom-claras. Entre as unhas tarsais das pernas II-IV, cerca de quatro fileiras de cerdas; ausentes no tarso I.

\section{REFERÊNCIAS BIBLIOGRÁFICAS}

Birabén, M. 1951. Fernandezina, nuevo género de Palpimanidae. Acta Zoologica Lilloana, Tucumán, 12:545-549.

Brescovit, A. D. \& Bonaldo, A. B. 1993. On the genus Otiothops in Brazil (Araneae, Palpimanidae). Bulletin de L'Institut Royal des Sciences Naturelles de Belgique Entomologie, Bruxelles, 63:47-50.

Grismado, C. J. 1996. Una nueva espécie de Otiothops Mac Leay de Argentina (Araneae, Palpimanidae). Revista del Museo Argentino de Ciencias Naturales "Bernardino Rivadavia", Nueva Serie, Buenos Aires, (130):1, 2.
_. 2002. Palpimanid spiders from Guyana: new species of the genera Fernandezina and Otiothops (Araneae, Palpimanidae, Otiothopinae). Iheringia, Série Zoologia, Porto Alegre, 92(3): 13-16.

Platnick, N. I. 1975. A revision of the palpimanid spiders of the new subfamily Otiothopinae (Araneae, Palpimanidae). American Museum Novitates, New York, (2562):1-32. 1976. A new Otiothops from Brazil (Araneae, Palpimanidae). Journal of the New York Entomological Society, New York, 84(3):178, 179.

1977. Notes on Chilean Palpimanidae (Arachnida, Araneae). The Journal of Arachnology, Austin, 3(3):203-205.

1978. A new Otiothops from Colombia (Araneae, Palpimanidae). The Journal of Arachnology, Austin, $\mathbf{5}(2): 179,180$.

- 1985. On the Chilean spiders of the family Palpimanidae (Arachnida, Araneae). The Journal of Arachnology, Blacksburg, 13(3):399, 400.

Platnick, N. I.; Grismado, C. J. \& Ramírez, M. J. 1999. On the genera of spider subfamily Otiothopinae (Araneae, Palpimanidae). American Museum Novitates, New York, (3257): $1-25$.

Ramirez, M. J. \& Grismado, C. J. 1996. A new Fernandezina from Brazil (Araneae, Palpimanidae). Iheringia, Série Zoologia, Porto Alegre, (80):117-119.

Wunderlich, J. 1999. Description of two new species of the genus Otiothops McLeay from South America (Arachnida: Araneae: Palpimanidae). Entomologische Zeitschrift, Stuttgart, 109(5):213-216. 